FaCUldade de FormaÇão de Professores

\title{
O ÚLTIMO DOS MOICANOS: PROTÓTIPO DA AVENTURA ROMÂNTICA
}

\author{
Loraci Hofmann Tonus (UTF/PR) \\ Márcia Oberderfer Consoli (UTF/PR) \\ marcia.consoli@hotmail.com
}

\section{FILOSOFIA ROMÂNTICA: \\ UM ESTILO CUJO ESPÍRITO PERMANECE}

O Romantismo foi um estilo de época da literatura ocidental que aflorou a partir dos ideais da Revolução Francesa e da ascensão econômica e política da burguesia. Ou seja, a partir da segunda metade do século XVIII, tomando força nas primeiras décadas do século XIX. Surgiu em um momento histórico de intensas transformações sociais e, de certa forma, enquanto estilo estético-literário, representou o desejo implícito de, ou colocar ordem no caos em que se haviam transformado as sociedades europeias - desejo esse que pode ser constatado na literatura de cunho panfletário, engajada na defesa de causas nobres - ou de evadir-se desse caos a partir da fuga da realidade, que se expressa na ambientação das histórias no passado histórico e na idealização de ambientes, de figuras humanas, de sentimentos e de relações sociais.

A concepção romântica da vida e da arte, de acordo com D’Onofrio (2002, p. 334), que usa a terminologia nietzschiana, “está ligada ao espírito 'dionisíaco', que simboliza a desordem, o instinto individual, as forças do subconsciente coletivo, a liberdade em todas as suas manifestações." Sob a égide dessa concepção, surge a aventura romântica, na qual o herói, geralmente de caráter indômito e rebelde, movido por sentimentos cavalheirescos tais como honra e proteção aos mais fracos, insurge-se contra situações que considera injustas para restabelecer a harmonia dos valores burgueses ou humanitários, obtendo, não raro, como prêmio, o consagrado final feliz.

Essas histórias com tais características se popularizaram durante os séculos XIX e XX, e esse gosto do público leitor por narrativas de cunho aventuresco tem sido explorado com frequência pelo cinema. Daí o sucesso de filmes em que o herói se envolve em missões para resolver problemas. Exemplos disso são personagens como 


\section{DEPARTAMENTO DE LETRAS}

Rambo, Indiana Jones, James Bond e, mais recentemente, Aragorn, de "O senhor dos anéis". Em todas essas histórias, romanticamente, o bem acaba por vencer o mal e isso apazigua, momentaneamente, a necessidade que o espectador tem de, enquanto indivíduo muitas vezes impotente diante das mazelas sociais, ver prevalecer a justiça.

"O último dos moicanos", lançado em 1992, é um filme de aventura que pode ser classificado como um protótipo dessas histórias com características românticas. O diretor Michael Mann baseouse no romance homônimo do escritor James Fenimore Cooper para mostrar a dimensão da tragédia humana durante as batalhas ocorridas na Guerra dos Sete Anos havida entre Inglaterra e França quando esses países disputavam territórios da costa leste da América do Norte, entre os anos de 1756 e 1763.

Protagonizam a história o caçador de peles Nathaniel Hawkeye, europeu, filho adotivo de índios moicanos, e Cora, filha do Coronel inglês Munro, um dos militares envolvidos no conflito. Nathaniel, auxiliado por Uncas e Chingachgook, respectivamente seu irmão e pai adotivos, consegue salvar as jovens Cora e Alice, ambas filhas de Munro, de um ataque dos índios hurons. Cora e Hawkeye apaixonam-se, porém essa história de amor é bastante dificultada pelas circunstâncias.

\section{O TEMPO E O ESPAÇO DA NARRATIVA}

A opção pelo passado histórico enquanto tempo da narrativa caracteriza uma das mais marcantes facetas da ficção romântica: a evasão, ou fuga da realidade.

A evasão no tempo, em "O último dos moicanos", é constatada logo no início da aventura, quando aparece na tela o ano de 1757 e a indicação do espaço narrativo: a fronteira entre as possessões territoriais da França e da Inglaterra, na América do Norte. Essa data e esse local remetem ao segundo ano da "guerra na qual a Inglaterra e a França disputaram pela última vez a posse de um país que nenhuma delas estava destinada a conservar sob o seu domínio" (Cooper, s/d, p. 4). 


\section{FaCUldade de FormaÇão de Professores}

Ressurgem, assim, como pano de fundo para a trajetória dos protagonistas românticos, os acontecimentos históricos que estabeleceram a definição territorial das colônias que vieram a constituir, mais tarde, os Estados Unidos e o Canadá. É então o clássico retorno às origens das nacionalidades que dá suporte à trama da narrativa. Essa escolha também propõe dar verossimilhança à história narrada ${ }^{10}$. Ou seja, se os acontecimentos históricos abordados são reais, por que não o seriam todos os personagens que se envolvem na trama ficcional?

Quanto ao cenário para o desenvolvimento da trama, ou seja, quanto ao espaço físico e social, o filme também corresponde ao modelo elaborado pelos escritores românticos.

A natureza é indomada: as grandes florestas, os rios caudalosos, permeados por corredeiras e grandes cachoeiras, as cavernas escuras quase inexploradas, as montanhas, os grandes precipícios, as ermas paragens, enfim, a natureza em seu estado mais selvagem e grandioso, definida por Bosi (1995, p. 102) como "expressiva", porque significa e revela. Porque comunga com os heróis os estados d'alma, a determinação férrea, o ímpeto guerreiro, o latejar contínuo das forças que impelem o indivíduo: os desejos, os sonhos, a honra, a paixão, o sacrifício.

Quanto ao espaço social em que se movimenta o herói Nathaniel, prevalece aquele gerado pelo convívio harmônico entre esse filho de homens brancos e os índios Chingachgook e Uncas. Esses últimos personificam o bom selvagem russoniano pois, na trama, revela-se grande o contraste entre a nobreza de caráter desses representantes da sociedade indígena e as falhas de personalidade encontradas nos demais personagens, sejam eles educados segundo os códigos culturais da civilização europeia ou sejam os indígenas já corrompidos pelo contato com os homens dessa civilização (D'Onofrio, 2002).

\footnotetext{
10 Lê-se em James Fenimore Cooper, no romance homônimo em que se baseia essa peça cinematográfica, que realmente ocorreram as batalhas pela conquista do Forte William Henry, bem como a rendição dos ingleses e o posterior massacre promovido pelos índios hurons com 0 assentimento tácito do general francês Montcalm.
} 


\section{DEPARTAMENTO DE LETRAS}

\section{A CONSTRUÇÃO ROMÂNTICA DE HERÓIS E HEROÍNAS}

Nathaniel, chamado Hawkeye pelos índios moicanos e Longa Carabina pelos inimigos da tribo huron por sua pontaria infalível no manejo de armas de fogo, é o homem branco que, desde criança foi educado pelo moicano Chingachgook. Assim tornou-se irmão de criação de Uncas e, por seu pouco contato com a civilização europeia, não teve seu caráter conspurcado por ela e pode, dessa forma, representar a síntese do que de mais nobre havia no homem branco e no guerreiro indígena.

Fisicamente, o herói Nathaniel é alto, forte e belo. Moralmente, é corajoso, destemido, inteligente e justo. Revolta-se contra os valores da civilização branca pois, no contexto histórico da trama, tais valores personificam a guerra, a ganância imperialista, a brutalidade e o desrespeito pelos demais seres humanos.

Outro herói da trama é o jovem guerreiro moicano Uncas, que partilha a existência com o pai, Chingachgook, e com o irmão branco, Nathaniel, e representa a última esperança de continuidade genealógica de um povo indígena praticamente extinto a partir do contato com os colonizadores europeus ${ }^{11}$. Uncas também é um herói com características românticas: fala pouco, mas suas ações, seus gestos e olhares revelam um caráter nobre, altivo e honrado. Uma única vez, no filme, é visto sorrindo, quando toma nos braços o filho pequeno do casal Cameron ${ }^{12}$. No restante do tempo da narrativa, já tragado,

11 Dee Brown, historiador revisionista americano, em Enterrem meu coração na curva do rio (1988), clássico estudo sobre o extermínio das tribos indígenas de seu país, faz diversas referências a respeito dos índios moicanos, das quais transcrevemos duas. A primeira, extraída da fala de Tecumseh, da tribo shawnee: Onde estão hoje os pequot? Onde estão os narragansett, os moicanos, os pokanoket, e muitas outras tribos outrora poderosas de nosso povo? Desapareceram diante da avareza e da opressão do Homem Branco, como a neve diante de um sol de verão (p.19). Na segunda, em texto do próprio escritor, lê-se uma referência direta a Uncas: Dispersos ou reduzidos a sobreviventes: os pequots (..) miamis, hurons, eries, mohawks, senecas e mohegans. (Só Uncas era lembrado). Seus nomes, que se celebrizaram na História da sua Pátria, permaneceram para sempre fixados na terra americana; mas seus ossos estavam abandonados, esquecidos em mil aldeias queimadas, perdidos em florestas que logo desapareceriam diante dos machados de 20 milhões de invasores (p.24).

12 Esse sorriso de Uncas parece simbolizar a satisfação com que o índio visualiza o próprio futuro. Como último jovem de sua espécie, ansiava por realizar os próprios desejos e os de seu pai, a partir da geração de prole que pudesse dar continuidade à sua espécie.

\section{SOLETRAS, Ano IX, N 17. São Gonçalo: UERJ, jan./jun.2009}




\section{FaCUldade de FormaÇão de Professores}

como os demais personagens, pelo turbilhão da guerra entre ingleses e franceses, Uncas empenha-se em proteger e amparar a jovem Alice, filha do Coronel inglês Munro.

Diferentemente dos demais guerreiros índios da trama, que se mostram ávidos por sangue e escalpos, Uncas, em sua essência, apresenta as características cavalheirescas do herói que, embora vivendo em bravias florestas, tem um destino épico a cumprir. Por tais características, é fácil relacioná-lo com o índio Peri, de José de Alencar (Gonzaga, 1994, p. 70). Tal como ocorre com Peri, a missão de Uncas relaciona-se à proteção e salvamento de uma heroína bela e branca, de ascendência europeia. Ambas, Alice ou Cecília, dependem somente da força e da determinação do herói para se manterem ilesas dos perigos que os inimigos e a natureza apresentam. Uncas, talvez mais convincentemente humano que Peri, que apresenta força física inexplicável, leva às últimas consequências essa disposição cavalheiresca, conforme se vê na análise das ações dos personagens.

As personagens femininas da trama também são adequadas às expectativas de caracterização física e psicológica e de ação dependente da proteção do herói, conforme o padrão estabelecido pela tradição dos textos românticos. Ambas as filhas do Coronel Munro são belas e frágeis, incapazes de se defenderem sozinhas dos perigos que as cercam. Mas são justamente essa beleza e fragilidade que motivam nos heróis o instinto de proteção peculiar ao espírito do Romantismo.

A beleza e feminilidade das personagens românticas são tradicionalmente idealizadas pelos autores, que se esmeram em descrever com riqueza de detalhes sua perfeição inigualável. Assim, pouco há de meramente humano nessa espécie de mulher-anjo. Nos romances europeus e norte-americanos, predominam as donzelas de pele invariavelmente muito branca, cabelos louros e olhos azuis. Essa tendência à idealização da mulher de ascendência europeia já proporcionou, na literatura brasileira, exageros descabidos como o cometido pelo autor de "A escrava Isaura". Lembremos a descrição dessa personagem. Isaura, fruto da união entre pai português e mãe africana, embora escrava, havia recebido educação esmerada, tocava piano e tinha a pele branca "como o marfim do teclado, alva que não deslumbra, embaçada por uma nuança delicada, que não sabereis di- 


\section{DEPARTAMENTO DE LETRAS}

zer se é leve palidez ou cor-de-rosa desmaiada" (Guimarães, 1975, p. 11). Isso denota, também, o arraigado preconceito contra mulheres de pele morena. Para ser uma heroína romântica, era necessário que houvesse na mulher algo de excepcionalmente belo. E o conceito de belo, na época, correspondia a ter pele muito, muito clara.

Essa criatura de excepcional beleza e candura normalmente é comparada às mais belas características da natureza, às quais sempre consegue superar, conforme se vê na descrição de Alice elaborada por Fenimore Cooper:

Uma delas, [...] cada vez que o ar da manhã lhe agitava o véu verde pendente do chapéu de castor, deixava entrever a sua tez maravilhosa, os lindos cabelos louros e os olhos azuis muito expressivos. A cor roxa que ainda para o ocidente tingia levemente o céu por cima dos pinheiros não era nem mais resplandecente nem mais delicada que a frescura das suas faces; nem tão pouco a luz do dia ao nascer do sol era mais alegre e animada que o sorriso concedido ao jovem oficial que a ajudara a montar (Cooper, s.d., p. 13-14).

A comparação da beleza de Alice com aspectos da natureza faz lembrar a índia Iracema, de José de Alencar, a qual "tinha os cabelos mais negros que a asa da graúna, e mais longos que seu talhe de palmeira. O favo da jati não era doce como seu sorriso; nem a baunilha recendia no bosque como seu hálito perfumado" (Alencar, 1994, p. 10). Eis, também, como é feita a descrição de Cora:

As tranças desta senhora eram negras e brilhantes como as asas do corvo. A sua tez não era morena, mas parecia antes deixar transparecer a cor do sangue opulento que se diria pronto a ultrapassar os seus limites. $\mathrm{E}$, contudo, não existia em sua aparência a mais leve falta de distinção nem dos requintes geralmente inerentes a uma senhora de nascimento ilustre, pois o seu porte era cheio de dignidade, além de as suas feições serem de inexcedível formosura (Cooper, s.d., p. 14-15).

No filme, Cora, mais velha que Alice, atua como protagonista por seu romance com Nathaniel. Mais corajosa e determinada que a irmã, a quem procura inutilmente proteger, Cora provoca em dois homens, em Nathaniel e no oficial inglês Duncan, sentimentos tão intensos quanto podem ser as paixões românticas, tornando-os capazes de qualquer sacrifício para garantirem seu bem estar. Mas é a jovem Alice, que tal como Uncas pouco fala durante o transcorrer da aventura e apresenta dificuldades para construir para si própria uma 


\section{FaCUldade de Formação de Professores}

identidade particular ou um espaço para ações independentes, quem protagoniza uma das cenas mais tocantes do clímax.

\section{O VILÃO: IDEALIZAÇÃO CONVENIENTE}

O índio Mágua, da tribo huron, caracteriza a figura do principal antagonista, pois nutre o desejo de vingar-se do coronel Munro, a quem responsabiliza pelo massacre de seus filhos. Tal como na Lei de Talião do olho por olho, Mágua também deseja exterminar as filhas de Munro para que este não deixe descendentes. Em seu confronto direto com o militar inglês, o índio porta-se com extrema crueldade e deixa antever um destino trágico para as donzelas que jura vitimizar.

Porém, Mágua, tal como tantos outros vilões das aventuras românticas, também tem sua parcela de idealização. Vê-se que o vilão, embora tenha diversas oportunidades de realizar seu intento de sacrificar Cora e Alice a partir do momento em que as faz prisioneiras, procrastina esse ato por razões pouco explicadas. Essa indecisão de Mágua é o fator que possibilita a ação dos heróis, dando-lhes tempo para organizarem estratégias de defesa. Fosse esse índio essencialmente, ou realisticamente mau, saciaria de imediato sua sede de vingança e a ação heróica de Nathaniel ou de Uncas seria tardia ou desnecessária.

Pode-se comparar as ações de Mágua às de Leôncio de "A escrava Isaura". Senhor de escravos, o perverso Leôncio deseja Isaura mas, tomando atitude contrária ao que se esperaria de alguém de sua época e de sua condição social, não age como os demais senhores de escravos, isto é, não força Isaura a manter com ele relacionamento carnal. Em uma história romântica, tal postura do vilão é necessária para manter a condição de pureza virginal da heroína, sem a qual se tornaria impossível o casamento com um rapaz de boa família burguesa. Ou seja, sem que existam mecanismos que coloquem um freio nos desejos obscuros dos vilões, parte do sentido desse tipo de história se perderia. Conforme Gonzaga (1994, p. 66), no romance romântico, "até os vilões sabem adaptar-se às conveniências. Só praticam a vilania enquanto o enredo assim o exige." No final, como requer o 


\section{DEPARTAMENTO DE LETRAS}

público leitor ou espectador, são severamente castigados, seja pelo herói, seja pelas circunstâncias.

Dessa forma, o assassinato de Mágua por Chingachgook não é questionado. Antes disso, é desejado pelo espectador. Sua dimensão humana, enquanto ser que teve seu universo invadido e a vida familiar e tribal destruída pelo colonizador, não é motivo de reflexão ou de angústia, já que sua reação à violência sofrida parece tão brutal e descabida. Assim, nesse universo de valores contraditórios, matar para proteger donzelas indefesas ou para vingar o fim do último descendente de uma tribo é ato aceito como plausível, um direito inquestionável. Porém, o mesmo benefício não é dado ao vilão. No caso de Mágua, a decisão passional de matar para vingar a morte dos próprios filhos é ato tão irracional que faz merecer, sem qualquer incômodo da consciência, a pena capital.

\section{A AÇÃO NA AVENTURA ROMÂNTICA}

De acordo com Platão e Fiorin (1993), a estrutura de qualquer narrativa se constitui de quatro partes essenciais que são: manipulação, competência, performance e sanção. Ou seja, as ações de uma narrativa são desencadeadas por alguém ou por algum fato (manipulação) que forçam dado personagem com determinadas características prévias ou necessárias (competência), a tomar certas atitudes (performance) que lhe trarão algum tipo de prêmio ou de castigo (sanção).

Por essa ótica vê-se que, no início da trama de "O último dos moicanos", tanto Nathaniel quanto Uncas e Chingachgook procuram ficar afastados do conflito de interesses que acaba por provocar a guerra entre ingleses e franceses. Quando instados a tomarem posição a favor dos ingleses, seus discursos revelam que pensam de forma crítica e independente e que recusam o engajamento a favor de uma causa avaliada como questionável.

Mas os heróis não conseguem manter por muito tempo a neutralidade e o não envolvimento que defendem, pois a avalanche dos acontecimentos os envolve, manipula e exige a ação heróica. Para Antônio Cândido (1975, p. 111), isso se dá porque, tal como no romance naturalista, que insiste em eleger o determinismo como fator 


\section{FaCUldade de FormaÇão de Professores}

primeiro para estabelecer o ciclo de atuação dos personagens, no Romantismo também prepondera o determinismo, que ocorre por motivação histórica ou passional. Ou seja, tanto autores naturalistas quanto românticos "se aplicavam em mostrar os diferentes modos por que a ação e o sentimento dos homens eram causados pelo meio, a paixão ou o organismo."

Dessa forma, no filme, Nathaniel, Uncas e Chingachgook, homens certos no lugar e momento certos, conseguem salvar as filhas do Coronel Munro do primeiro ataque promovido pelo vilão Mágua, que tinha o intuito de lhes tirar a vida. Têm competências para assim agirem, pois conhecem o ambiente onde se movem, lutam com extrema agilidade, manipulam com muita segurança as armas de que dispõem e, principalmente, têm as necessárias qualidades de caráter, conforme já mostrado, que os faz agirem em defesa dos mais fracos. Isso porque, para ser um herói, romântico ou não, no verdadeiro sentido do termo, não basta que o personagem queira ou deva, mas que também saiba e possa (Platão \& Fiorin, 1993).

Dentre as inúmeras performances que ocorrem na trama, algumas são típicas da tradição romântica, como os sacrifícios extremos que os personagens fazem por amor. Nas dramáticas cenas finais, quando o velho líder indígena huron decreta a morte de Cora na fogueira para vingar os filhos de Mágua, tanto Nathaniel quanto Duncan se oferecem para morrer em seu lugar. Porém Duncan, o único a conseguir estabelecer diálogo com o chefe índio, propõe a troca que, aceita, acaba por vitimizá-lo. Com essa imolação voluntária, fruto de uma situação desesperadora em que a vida da mulher que ama está por um fio, Duncan se redime dos erros cometidos e se torna o responsável direto pela felicidade futura de Cora e de Nathaniel. Mas, em última instância, é a arma de Nathaniel que dá fim ao sofrimento de Duncan. Isso permite estabelecer relação intertextual com o clássico romance de Goethe, "Werther" ${ }^{13}$, cujo personagem tí-

${ }^{13}$ Os sofrimentos do jovem Werther é considerado o primeiro romance romântico da literatura universal. Escrito por Johann Wolfgang Goethe e publicado na Alemanha em 1774, lançou as bases do sentimentalismo romântico e do escapismo pelo suicídio. Ficou proibido durante décadas na Europa, pois Werther se suicida para fugir de seus sofrimentos amorosos e tal atitude passou a ser imitada pelos jovens europeus que consideravam belo morrer de amor na flor da idade. 


\section{DEPARTAMENTO DE LETRAS}

tulo também morre voluntariamente pela arma de Albert, marido de Charlotte, a mulher a quem Werther ama desesperadamente.

Mas, em "O último dos moicanos", Duncan não é o único personagem a se sacrificar pela mulher que ama. Tal gesto de extremo desprendimento também pode ser observado nas ações de Uncas que, nas cenas finais, impulsionado por um sentimento de urgência, age sozinho para salvar Alice que se encontra prisioneira de Mágua. Embora poucas cenas do filme levem o espectador a considerar a existência de uma paixão de Uncas por Alice, o extremo sacrifício do jovem índio permite avaliar esse amor como desmesurado. Vê-se que, impensadamente, Uncas arrisca a vida e, consequentemente, a continuidade genealógica da tribo moicana em nome de uma paixão que sequer sabe se é correspondida. Assim, morto cruelmente por Mágua após atacar com ímpeto guerreiro e mortal diversos índios do séquito desse chefe huron, Uncas recebe a morte como sanção por seus atos irrefletidos e, dessa forma, reforça o mito do jovem herói romântico que morre por amor.

Já o suicídio de Alice apresenta outra conotação. Colocada involuntariamente em uma situação de extremo perigo, fica sem saída ao presenciar o fracasso da tentativa de ajuda que faz Uncas, seu protetor. Por isso, a moça entrega-se à morte como evasão de uma realidade tão trágica e inconcebível para um espírito sensível como o de uma heroína romântica. Antes a morte voluntária que a degradação física e moral. Quando vê a faca ensanguentada na mão de Mágua, Alice pula no precipício. Seu corpo cai no abismo ao lado do de Uncas e essa cena é simbólica de uma proximidade perpétua que os personagens passariam a ter após a morte física. A natureza como refúgio é outra característica do Romantismo que é marcante nessas cenas finais, pois é o espaço abissal que apresenta para Alice a possibilidade de evadir-se da realidade.

$\mathrm{Na}$ Literatura, e não unicamente no Romantismo, são inúmeros os casos em que ocorre a morte da heroína que perde a vontade de viver quando vê seus projetos amorosos serem desenganados. $\mathrm{Na}$ lembrança imediata surgem os nomes de Julieta, Moema, Lindoia, 


\section{FaCUldade de Formação de Professores}

Teresa, Inocência ${ }^{14}$ e tantas outras que se evadem para dimensões nas quais supõem que o sentimento de perda e de sofrimento seja minimizado.

Quanto à história de amor entre Cora e Nathaniel, no desfecho da narrativa fica implícito para o espectador a possibilidade de o casal obter uma sanção positiva, isto é, uma continuidade na convivência que pode trazer o "final feliz", embora não instantâneo, pois esse amor é marcado por tragédias pessoais e familiares que precisam ser superadas.

\section{ÚLTIMAS CONSIDERAÇÕES}

Nathaniel Hawkeye, o herói branco do filme, protagoniza todos os romances da série "Leatherstocking Tales", escrita por James Fenimore Cooper. Hawkeye recebe outros nomes nessas novelas, a saber, Meias de Couro, Olho de Falcão, Nathaniel Bumpo, Longa Carabina, Pathfinder e Leatherstocking Man.

O filme, embora baseado na novela desse escritor americano, apresenta com essa obra pouca verossimilhança na construção de personagens e no desenvolvimento das ações. Excetuam-se dessa constatação o contexto histórico, o cenário natural e grandioso e a caracterização física das heroínas. $\mathrm{Na}$ verdade, o filme é o clássico revisitado, é uma leitura nova que apresenta uma outra visão, mais moderna e menos preconceituosa, do contato entre brancos e índios.

Didaticamente, sugerimos assistir a esse filme com alunos do Ensino Médio para analisar, a partir dele, as características do Romantismo. Consideramos o cinema um valioso recurso pedagógico que, se devidamente explorado, pode contribuir para o enriquecimento do currículo.

${ }^{14}$ Essas personagens são protagonistas, respectivamente, das seguintes obras: Romeu e Julieta, peça de William Shakespeare; Caramuru, poema épico de Frei de Santa Rita Durão; O Uraguai, poema épico de Basílio da Gama; Amor de Perdição, romance de Camilo Castelo Branco; e Inocência, romance de Visconde de Taunay. 


\section{DEPARTAMENTO DE LETRAS}

\section{REFERÊNCIAS}

ALENCAR, J. Iracema. São Paulo: Scipione, 1994.

BOSI, A. História concisa da literatura brasileira. $3^{\text {a }}$ ed. São Paulo: Cultrix, 1995.

BROWN, D. Enterrem meu coração na curva do rio. São Paulo: Círculo do Livro, 1988.

CÂNDIDO, A. Formação da literatura brasileira: momentos decisivos. $5^{\text {a }}$ ed. Belo Horizonte: Itatiaia, 1975.

COOPER, J. F. O último dos moicanos. Rio de Janeiro: W. M. Jackson Inc., s.d.

D'ONOFRIO, S. Literatura ocidental: autores e obras fundamentais. $2^{a}$ ed. São Paulo: Ática, 2002.

GONZAGA, S. Manual de literatura brasileira. $11^{\mathrm{a}}$ ed. Porto Alegre: Mercado Aberto, 1994.

GUIMARÃES, B. A escrava Isaura. $4^{\mathrm{a}}$ ed. São Paulo: Ática, 1975.

MANN, M. O último dos moicanos. EUA, 1992. 122 min. Título original: The last of mohicans.

PLATÃO, F. \& FIORIN, J. L. Para entender o texto. $7^{\text {a }}$ ed. São Paulo: Ática, 1993. 